\title{
Drug utilization pattern among pregnant women attending maternal and child health clinic of tertiary hospital in eastern Ethiopia: Consideration of toxicological perspectives
}

\author{
Neim Bedewi ${ }^{1}$, Mekonnen Sisay ${ }^{2^{*}}$ (1) and Dumessa Edessa ${ }^{3}$
}

\begin{abstract}
Objective: This study is aimed to investigate drug utilization pattern among pregnant women attending maternal and child health clinic of tertiary hospital in eastern Ethiopia from March 1 to April 20, 2018.

Result: A total of 369 pregnant women medical records were reviewed. The mean age of pregnant women was 24.34 ( \pm 4.48$)$ years and the majority of them were within the age of $18-25$ years. About three-fourths $(n=277,75.1 \%)$ of them were urban residents. Besides, 314 (85.1\%) women had taken at least one drug with a total of 377 drugs prescribed. From which, supplemental drugs accounted majority of the drug therapy (84.88\%) whereas non-supplemental drugs (15.12\%) were used by 41 pregnant women during the review period. According to Food and Drug Administration FDA pregnancy risk classification, 320 (84.88\%) drugs were prescribed from category A; 33 (8.75\%) drugs were from category B; 19 (5.04\%) drugs were from category C and 5 (1.33\%) drugs were from category D. There was no drug prescribed from category $X$. As this result indicated, there is a decrease in the prevalence of drug use from Category $A$ to $X$ as the possibility of potential risk to fetus might outweigh the potential benefit to the mother. Some drugs were utilized from category $D$ for treatment of chronic illnesses.
\end{abstract}

Keywords: Drug utilization, Pregnancy, Tertiary hospital

\section{Introduction}

Despite the lack of adequate studies on safety of prescription drugs for pregnant women, available evidence has shown that healthcare professionals prescribe and pregnant women take a surprisingly large number of drugs. Furthermore, $86 \%$ of the women had taken at least one prescription medication during their pregnancies. Despite several physiological, pharmacokinetic and pharmacodynamic changes occurring during pregnancy, pregnant women are still considered therapeutic orphans, since the majority of available drugs were not adequately studied in pregnancy [1-4].

\footnotetext{
*Correspondence: mekonnensisay27@yahoo.com

2 Department of Pharmacology and Toxicology, School of Pharmacy, College of Health and Medical Sciences, Haramaya University, P.O.Box, 235, Harar, Ethiopia

Full list of author information is available at the end of the article
}

Pregnant women have been often excluded from clinical trials and evidences generated from animal-based studies are not often suitable for extrapolation to indicate teratogenicity in humans. Hence, drug use by pregnant women is considered experimental in most clinical practices. However, the use of medications is sometimes mandatory in the treatment of women of reproductive age, breast feeding and during pregnancy $[5,6]$. Healthcare professionals should ensure that optimal medications are prescribed when treating women of childbearing potential with chronic diseases [7].

A large number of studies have been conducted in developing and developed countries. Most of them have reported the utilization of large number of drugs during pregnancy with substantial number of drugs from category D and X of Food and Drug administration (FDA) pregnancy risk categories [8]. Although it seems rare, previous studies demonstrated that the use of drugs from 
FDA pregnancy risk category $\mathrm{X}$ had been observed during pregnancy [9-12]. This study is, therefore, designed to investigate the drug utilization pattern and toxicological perspectives among pregnant women attending tertiary hospital in eastern Ethiopia.

\section{Main texts \\ Methods \\ Study area, design and period}

The study was conducted at Hiwot Fana Specialized University Hospital (HFSUH), Harar which is located $526 \mathrm{~km}$ away from Addis Ababa to the east. There are three governmental hospitals in Harar town and HFSUH was purposely selected as it is a tertiary care teaching hospital of Haramaya University and hosts majority of patient attendees from Harar city and its surrounding. An institution-based cross-sectional study was conducted from March 1 to April 20, 2018 on one year medical records (from September 1, 2016 to August 31, 2017) of pregnant women attending maternal and child health $(\mathrm{MCH})$ clinic of the hospital.

\section{Study population}

All medical records of pregnant women who attended MCH clinic of HFSUH from Sep 1, 2016 to Aug 31, 2017 were considered as study population from which sampling units were drawn.

\section{Sample size determination and sampling techniques}

The sample size determination was performed according to single population proportion formula as shown hereunder

$$
\begin{aligned}
\mathrm{n} & =\frac{z^{2} p(1-p)}{d^{2}}=\frac{(1.96)^{2} * 0.875(1-0.875)}{(0.03)^{2}} \\
& =466.86 \sim 467
\end{aligned}
$$

where, $\mathrm{p}=$ prevalence/proportion of drug use during pregnancy, $87.5 \%$ [8], $\mathrm{d}=$ margin of error which is $3 \%$, $\mathrm{z}=$ confidence level at $95 \%=1.96$. The size of study population per year (the total number of pregnant women who had follow up during the review period) was found to be $1410(<10,000)$. Thus, adjustment had been performed to get the final sample size

$$
\boldsymbol{n}_{\boldsymbol{f}}=\frac{\boldsymbol{n i}}{1+\frac{\boldsymbol{n i}}{\boldsymbol{N}}}=\frac{467}{1+\frac{467}{1410}}=351
$$

where; $\boldsymbol{n}_{\boldsymbol{f}}=$ final sample size; $\mathrm{ni}=$ initial sample size; $\mathrm{N}=$ Study population. Up on adding $5 \%$ methodological contingency, the final sample size was found to be 369 . Simple random sampling was applied to obtain sampling units (medical records).
Table 1 Socio-demographic characteristics of pregnant women attending MCH clinic of HFSUH, eastern Ethiopia

\begin{tabular}{lc}
\hline Variables and category & Frequency (\%) \\
\hline Age (years) & \\
$<18$ & $31(8.4)$ \\
$18-25$ & $201(54.5)$ \\
$26-30$ & $107(29.0)$ \\
$>30$ & $30(8.1)$ \\
Gravidity & \\
Primigravida & $149(40.4)$ \\
Multigravida & $220(59.6)$ \\
Area of resident & \\
Urban & $277(75.1)$ \\
Rural & $92(24.9)$ \\
\hline
\end{tabular}

\section{Data collection processes}

Data abstraction format containing socio-demographics (Age, gravidity and resident), clinical and drug related variables (Trimester of pregnancy, supplemental and other drugs utilization and medical conditions diagnosed during pregnancy), FDA pregnancy risk categories and prevalence of components of dosage regimen was utilized to extract important information from medical records.

\section{Pretest and data quality control}

Pretest was conducted in Jugel hospital, found in the same town, for the sake of amending the data collection tool to best fit the existing context. Data collecting format was also cross-matched with available information on records. Data cleaning was performed on daily basis. Incomplete charts were discarded.

\section{Data processing and analysis}

The data were coded, entered and analyzed by using Statistical Package for Social Sciences (SPSS) version 20 (IBM statistics, Armonk, NY, USA). Data were presented in tables and figure.

\section{Results}

\section{Socio-demographic characteristics}

A total of 369 pregnant women medical records were reviewed for this study. From these, the larger proportion of women $220(59.62 \%)$ were found multigravida. The mean age of pregnant women was 24.34 $( \pm 4.48)$ years and the majority of them were within the age of 18-25 years. About three-fourths $(\mathrm{n}=277,75.1 \%)$ of them were urban residents (Table 1 ). 


\section{Clinical and drug use characteristics}

From the total of 369 pregnant women, 314 (85.1\%) had taken at least one drug. A total of 377 drugs were prescribed for such pregnant women, from which supplemental drugs accounted majority of the drug therapy $(\mathrm{n}=320,84.88 \%)$ whereas non-supplemental drugs $(\mathrm{n}=57,15.12 \%)$ were used by 41 pregnant women during the review period. Among supplemental drugs, iron/ folate combinations were found predominately prescribed medications $(\mathrm{n}=313 ; 97.81 \%)$ with the highest consumption seen in the 1st and 2nd trimester. The average number of drugs prescribed per pregnant women was found to be 1.21. From non-supplemental drugs, antibiotics were the most commonly prescribed drugs followed by gastrointestinal drugs. From pregnant women prescribed with non-supplemental drugs, there was no recorded diagnosis on seven pregnant women medical records; 29 women had been diagnosed with acute illnesses (by considering three pregnant women with two diagnoses each). From acute illnesses, dyspepsia and urinary tract infection took the largest percentage share. Five pregnant women had been diagnosed with chronic illnesses (Table 2). Excluding iron/folate, 39, 14 and 11 drugs were used during the first, second and third trimester of pregnancy, respectively (Table 3 ).

\section{FDA pregnancy risk categories}

From a total of 377 drugs prescribed for pregnant women, $320(84.88 \%)$ drugs were prescribed from FDA pregnancy risk category A; 33 (8.75\%) drugs were from category B; 19 (5.04\%) drugs were from category C and the rest $5(1.33 \%)$ drugs were prescribed from category $\mathrm{D}$. There was no drug prescribed from FDA pregnancy risk category $\mathrm{X}$ in this study (Table 3 ).

\section{Dosage regimen related information}

For supplemental drugs, only the drug name was stated and no other dosage regimen components specified. Upon investigating the components of dosage regimen for non-supplemental drugs, dosage form and strength were not recorded at all on medical records. Dose and frequency were written in almost all medical records $(\mathrm{n}=56,98.24 \%)$ followed by route of administration and duration of therapy, which were written on 48 (84.21\%) and $23(40.35 \%)$ patient medical records, respectively (Additional file 1: Figure S1).

\section{Discussion}

Prescription medication use during pregnancy has become a common practice in many settings. Physicians prescribe and women use medicines with possibility of
Table 2 Frequency distribution of iron/folate used across trimesters, drug category utilized and medical conditions diagnosed among pregnant women attending MCH clinic of HFSUH, eastern Ethiopia from September 1, 2016 to August 31, 2017

\begin{tabular}{|c|c|}
\hline Clinical and drug related variables & Frequency (\%) \\
\hline \multicolumn{2}{|l|}{ Iron/folate use by Trimester of pregnancy } \\
\hline $1 \mathrm{st}$ & $99(31.63)$ \\
\hline 2nd & $74(23.64)$ \\
\hline $3 r d$ & $44(14.06)$ \\
\hline 1 st and 2 nd & $32(10.22)$ \\
\hline 1 st and 3rd & $16(5.11)$ \\
\hline 2nd and 3rd & $25(7.99)$ \\
\hline Throughout the gestation & $23(7.35)$ \\
\hline Total & $313(100)$ \\
\hline \multicolumn{2}{|l|}{ Drug category used during pregnancy } \\
\hline Antibiotics & $22(5.3)$ \\
\hline Gastro-intestinal drugs & $17(4.51)$ \\
\hline Analgesics & $9(2.39)$ \\
\hline Vitamins and minerals (supplemental) & $320(84.88)$ \\
\hline Others $^{a}$ & $9(2.92)$ \\
\hline \multicolumn{2}{|c|}{ Medical condition diagnosed in pregnant women } \\
\hline Acute illnesses & $29(70.73)$ \\
\hline Amebiasis & $2(6.9)$ \\
\hline Common cold & $1(3.45)$ \\
\hline Dyspepsia & $9(31.03)$ \\
\hline H. pylori infection & $1(3.45)$ \\
\hline Hyper-emesis (morning sickness) & $5(17.24)$ \\
\hline Pneumonia & $5(17.24)$ \\
\hline Urinary tract infections & $6(20.69)$ \\
\hline Chronic illnesses & $5(12.19)$ \\
\hline Asthma & $2(40.0)$ \\
\hline Bipolar without psychotic feature & $1(20.0)$ \\
\hline Epilepsy & $1(20.0)$ \\
\hline HIV/AIDS & $1(20.0)$ \\
\hline
\end{tabular}

a Respiratory drugs, anti-convulsant, anti-psychotic, corticosteroids

risks and without critically judging how harmful it may be for both mother and fetus [13-15]. In this study, the prevalence of drug use during pregnancy was found to be $85.1 \%$. This value was comparable with the study conducted in northern Ethiopia [8] and Bahirdar city [12] where the prevalence of drug use during pregnancy was found to be $87.5 \%$ and $88.4 \%$, respectively. With reference to this finding, lower and higher drug utilization were also reported in studies conducted at Ayder referral hospital, Mekele (62.2\%) [16] and Nekemte town (96\%) [17], respectively. Almost half of the drug used in the current finding was during the first trimester of pregnancy where the critical period of organogenesis lies and drug-induced teratogenicity is assumed to reach climax. Generally, drug use during pregnancy should be in compassionate 
Table 3 Medications used by pregnant women at different trimesters and their US FDA pregnancy risk classification in HFSUH, eastern Ethiopia from September 1, 2016 to August 31, 2017

\begin{tabular}{|c|c|c|c|c|c|}
\hline Drug name & $\begin{array}{l}\text { 1st trimester } \\
\text { Frequency }\end{array}$ & $\begin{array}{l}\text { 2nd trimester } \\
\text { Frequency }\end{array}$ & $\begin{array}{l}\text { 3rd trimester } \\
\text { Frequency }\end{array}$ & $\begin{array}{l}\text { Total } \\
\text { Frequency }\end{array}$ & $\begin{array}{l}\text { FDA risk } \\
\text { category }\end{array}$ \\
\hline Amoxicillin & 3 & 4 & 0 & 7 & B \\
\hline Augmentin & 1 & 0 & 0 & 1 & B \\
\hline Azithromycin & 4 & 1 & 0 & 5 & B \\
\hline Carbamazepine & 2 & 0 & 0 & 2 & D \\
\hline Ceftriaxone & 1 & 0 & 0 & 1 & B \\
\hline Cephalexin & 1 & 1 & 1 & 3 & B \\
\hline Cimetidine & 2 & 1 & 2 & 5 & B \\
\hline Cotrimoxazole & 1 & 0 & 0 & 1 & $\mathrm{D}$ \\
\hline Chlorpromazine & 4 & 0 & 0 & 4 & C \\
\hline Diazepam & 1 & 0 & 0 & 1 & $\mathrm{D}$ \\
\hline Diclofenac & 3 & 0 & 0 & 3 & C \\
\hline Diphenhydramine & 0 & 1 & 0 & 1 & B \\
\hline Haloperidol & 1 & 0 & 0 & 1 & C \\
\hline Hydrocortisone & 1 & 0 & 0 & 1 & C \\
\hline Iron/folate ${ }^{a}$ & $\checkmark$ & $\checkmark$ & $\checkmark$ & 313 & A \\
\hline Mebendazole & 1 & 0 & 0 & 1 & C \\
\hline Metoclopramide & 1 & 1 & 0 & 2 & B \\
\hline Metronidazole & 0 & 1 & 1 & 2 & B \\
\hline MTS & 1 & 0 & 1 & 2 & $C$ \\
\hline Multi-vitamin ${ }^{a}$ & 4 & 1 & 2 & 7 & A \\
\hline Omeprazole & 1 & 1 & 1 & 3 & C \\
\hline Paracetamol & 2 & 2 & 0 & 4 & B \\
\hline Prednisolone & 1 & 0 & 0 & 1 & D \\
\hline Salbutamol & 1 & 0 & 1 & 2 & C \\
\hline $\mathrm{TDF}+3 \mathrm{TC}+\mathrm{EFV}$ & 1 & 0 & 0 & 1 & C \\
\hline Tramadol & 1 & 0 & 1 & 2 & B \\
\hline Triple therapy & 0 & 0 & 1 & 1 & C \\
\hline Total & $39^{\mathrm{b}}$ & $14^{\mathrm{b}}$ & $11^{\mathrm{b}}$ & $64^{\mathrm{b}}(377)$ & \\
\hline
\end{tabular}

a Supplemental drug $\checkmark$ given throughout the pregnancy

b Drugs other than Iron/folate; the number in parenthesis indicates the total number of drugs including iron/folate

manner and there must be vivid information justifying the potential benefit to the mother and the potential risk to the fetus.

Supplemental drug utilization accounted for $84.88 \%$ of total drug used, iron/folate utilization took $97.81 \%$ of supplemental drug therapy, which was by far higher than a study conducted in eight rural districts of Ethiopia where only $35.4 \%$ of pregnant women used iron supplements [18]. Study conducted in Addis Ababa [19] was somewhat in similar pattern of iron/folate utilization with the present study. The lower value observed in rural districts might be, in part, related to low health service coverage, distance from healthcare settings and awareness about the importance of such supplements for pregnant women.

Antibiotics were the most utilized medications from non-supplemental drugs in this study. This finding was found in concordant with previous studies conducted in HFSUH [20] and Adama referral hospital [1]. From toxicological perspectives, majority of antibiotics were from penicillins, cephalosporins and macrolids and all of which are actually from pregnancy risk category $B$ where either animal reproductive studies have not demonstrated fetal risks but no controlled studies in pregnant women have been reported, or animal reproductive studies have shown an adverse effect that was not confirmed in controlled studies in women in the first trimester [21]. Maternal use of antibiotics during pregnancy has been associated with an increased risk of otitis media and ventilation tube insertions in the offspring [22]. During pregnancy, pharmacokinetic alterations in antibiotics require dose adjustment or careful monitoring and assessment $[4,23]$. Antibiotic use during pregnancy has also shown a risk of spontaneous abortion and congenital malformations in the first trimester [24-27]. 
Looking at the overall distribution of drug utilization, majority of the drugs was from FDA category A (84.88\%). This finding was in line with a study conducted in northern Ethiopia [8] where high number of drugs was used from this category. However, this finding had shown a gap from the study conducted in Sao Paulo, Brazil [28] and Fiche hospital, Ethiopia [29] in which only 20.55\% and $20.83 \%$, respectively, were from category A. The study conducted in a tertiary care hospital, India indicated that $91.13 \%$ of drugs used during pregnancy were from this category and was found slightly higher than the present finding [30]. In this study, $8.75 \%$ of drugs used were from FDA category B. This finding was in line with the study conducted in northern Ethiopia (7.9\%) [8]. Higher prevalence of drug use was reported from studies conducted in Jimma [10] and western Nepal [31] where $48.7 \%$ and $60.2 \%$ of drugs were prescribed from FDA category B.

The use of category $\mathrm{C}$ drugs in this study was somewhat similar with the study conducted in urban heath center of Nanded where only $4.28 \%$ of drugs constituted this category [32]. In the present study, there were 5 (1.33\%) drugs from FDA-category D and all of them were used for chronic illnesses. These drugs were the least utilized from FDA pregnancy risk category drugs which was in line with that of the study conducted in Brazil (1.85\%) [28] and in Coastal town, India (3.13\%) [33] where medications used for pregnant women were from this category. A study conducted in Addis Ababa [34] had a higher value than this finding whereas a study conducted in Ahmedabad, India revealed that there was no drug used from this category [35]. In category D, there is positive evidence of human fetal risk based on adverse reaction data from investigational or marketing experience or studies in humans, but potential benefits may warrant use of these drug in pregnant women despite potential risks [21]. In the current finding there was no drug used from FDA category $\mathrm{X}$. This was similar with the study conducted in Adama [1], northern Ethiopia [8] and Banglore [36]. Studies indicated that there was a practice of prescribing drugs from category $\mathrm{X}$ in Omani $(0.3 \%)$ [9], in Brazil (0.03\%) [28], in Jimma, Ethiopia (7.4\%) [10], in Bahirdar, Ethiopia (5.5\%) [12], and in United States (4.6\%) [11].

The FDA five letter system (A, B, C, D and X) of pregnancy risk category has been used since 1979 . This system highlights toxicological consideration of drug use during pregnancy based on some evidences collected from preclinical and clinical trials. However, there are backlashes from customers to FDA forcing it to revise this letter system into new narrative system. While the new labeling improves the old format, it still does not provide a definitive "yes" or "no" answer in most cases. Clinical interpretation is still required on a case-by-case basis. The new system actually considers nursing mothers and males and females of reproductive potential [21].

\section{Conclusion}

Most of the drugs utilized were supplemental in nature. There was no drug utilized by pregnant women from FDA pregnancy risk category X. Some drugs were utilized from FDA category D for life threatening chronic illnesses, despite the fact that some drugs might have risk for pregnant women and for which they have safe alternatives during pregnancy. There was insufficient drug information on patients' medical records and some patient medical records didn't have diagnosis for the prescribed drugs at all.

\section{Limitations}

This study tried to address the overall drug utilization pattern during pregnancy. However, the study was not without limitations. This is a cross sectional study which couldn't address the temporal relationship of drug exposure and pregnancy risk. Besides, the study utilized the old letter (A-X) system of FDA pregnancy risk categories which seem overly simplified despite the fact that the new narrative system has no cut-off point (requires critical judgment) and couldn't be studied with retrospective chart review.

\section{Additional file}

Additional file 1: Figure S1. Dosage regimen related information on medical records of pregnant women for non-supplemental drugs.

\section{Abbreviations}

FDA: Food and Drug Administration; HFSUH: Hiwot Fana Specialized University Hospital; MCH: maternal and child health.

\section{Authors' contributions}

NB and MS conceived the study and drafted the proposal. NB, MS and DE had substantial contribution in the study design and development of data collection checklist. All authors were also involved in data acquisition, analysis, interpretation and write-up. MS and DE were also involved in drafting the manuscript, critical revision and preparation of the final draft for publication. All authors read and approved the final the manuscript.

\section{Author details}

${ }^{1}$ School of Pharmacy, College of Health and Medical Sciences, Haramaya University, P.O.Box, 235, Harar, Ethiopia. ${ }^{2}$ Department of Pharmacology and Toxicology, School of Pharmacy, College of Health and Medical Sciences, Haramaya University, P.O.Box, 235, Harar, Ethiopia. ${ }^{3}$ Department of Pharmacy Practice, School of Pharmacy, College of Health and Medical Sciences, Haramaya University, P.O. Box, 235, Harar, Ethiopia. 


\section{Acknowledgements}

Authors thank data collectors and MCH clinic staffs of HFSUH without them this research would not be realized.

\section{Competing interests}

The authors declared that they have no competing interests.

\section{Availability of data and materials}

All the data used for the study is contained within the manuscript and Additional file 1: Figure $\mathrm{S} 1$.

\section{Consent for publication}

Not applicable.

\section{Ethical approval and consent to participate}

Study approval and ethical clearance was sought and received from Haramaya University, College of Health and Medical Sciences, School of Pharmacy. Official permission was then received from hospital administrator to start the study. Voluntary, informed, written and signed consent was also obtained from head of the hospital after the purpose of the study had been introduced. Confidentiality of the collected data was maintained in such a way that the data collection tool was kept anonymous.

\section{Funding statement}

Authors disclosed no reception of financial support from any organization/ institution for conducting this research work.

\section{Publisher's Note}

Springer Nature remains neutral with regard to jurisdictional claims in published maps and institutional affiliations.

Received: 2 November 2018 Accepted: 29 November 2018

Published online: 04 December 2018

\section{References}

1. Belay M, Kahaliw W, Ergetie Z. Assessment of drug utilization pattern during pregnancy in Adama Riferral Hospital, Oromia Region, Ethiopia. Int J Pharm Sci Res. 2013;4(5):1905-11.

2. Ayad M, Costantine MM. Epidemiology of medications use in pregnancy. Seminars in perinatology. 2015;2015:508-11.

3. Yates $L M$, Thomas SH. Prescribing medicines in pregnancy. Medicine. 2016;44(7):438-43.

4. Bookstaver PB, Bland CM, Griffin B, Stover KR, Eiland LS, McLaughlin M. A review of antibiotic use in pregnancy. Pharmacotherapy. 2015;35(11):1052-62.

5. Van Gelder MM, Van Rooij IA, Miller RK, Zielhuis GA, de Jong-van den Berg LT, Roeleveld N. Teratogenic mechanisms of medical drugs. Hum Reprod Update. 2010;16(4):378-94.

6. Bhingare PE, Bashir MSM, Khade A, George S. Prescription pattern in gynecology-a retrospective study in a South Indian Teaching Hospital. Drugs. 2014:3:7-9.

7. Cleary BJ, Butt H, Strawbridge JD, Gallagher PJ, Fahey T, Murphy DJ. Medication use in early pregnancy-prevalence and determinants of use in a prospective cohort of women. Pharmacoepidemiol Drug Saf. 2010:19(4):408-17.

8. Molla F, Assen A, Abrha S, Masresha B, Gashaw A, Wondimu A, Belete Y, Melkam W. Prescription drug use during pregnancy in Southern Tigray region, North Ethiopia. BMC Preg Childbirth. 2017;17(1):170

9. Al-Riyami IM, Al-Busaidy IQ, Al-Zakwani IS. Medication use during pregnancy in Omani women. Int J Clin Pharm. 2011;33(4):634-41.

10. Mohammed MA, Ahmed JH, Bushra AW, Aljadhey HS. Medications use among pregnant women in Ethiopia: a cross sectional study. J Appl Pharm Sci. 2013;3(4):116.

11. Andrade SE, Gurwitz JH, Davis RL, Chan KA, Finkelstein JA, Fortman K, McPhillips H, Raebel MA, Roblin D, Smith DH. Prescription drug use in pregnancy. Am J Obstet Gynecol. 2004;191(2):398-407.
12. Admasie C, Wasie B, Abeje G. Determinants of prescribed drug use among pregnant women in Bahir Dar city administration, Northwest Ethiopia: a cross sectional study. BMC Preg Childbirth. 2014;14(1):325.

13. Daw JR, Hanley GE, Greyson DL, Morgan SG. Prescription drug use during pregnancy in developed countries: a systematic review. Pharmacoepidemiol Drug Saf. 2011;20(9):895-902.

14. Lupattelli A, Spigset O, Twigg MJ, Zagorodnikova K, Mårdby A-C, Moretti ME, Drozd M, Panchaud A, Hämeen-Anttila K, Rieutord A. Medication use in pregnancy: a cross-sectional, multinational web-based study. BMJ Open. 2014;4(2):e004365

15. Engeland A, Bjørge T, Klungsøyr K, Hjellvik V, Skurtveit S, Furu K. Trends in prescription drug use during pregnancy and postpartum in Norway, 2005 to 2015. Pharmacoepidemiol Drug Saf. 2018. https://doi. org/10.1002/pds.4577.

16. Gebreegziabher TL, Berhe DF, Gutema GB, Kabtyimer BN. Drug utilization pattern and potential teratogenesity risk among pregnant women; the case of Ayder referral hospital, Tigray-Ethiopia. Int J Pharm Sci Res. 2012;3(5):1371

17. Asfaw F, Bekele M, Temam S, Kelel M. Drug utilization pattern during pregnancy in Nekemte referral hospital: a cross sectional study. Int J Sci Rep. 2016;2(8):201-6.

18. Gebremedhin S, Samuel A, Mamo G, Moges T, Assefa T. Coverage, compliance and factors associated with utilization of iron supplementation during pregnancy in eight rural districts of Ethiopia: a cross-sectional study. BMC Public Health. 2014;14(1):607.

19. Gebreamlak B, Dadi AF, Atnafu A. High adherence to iron/folic acid supplementation during pregnancy time among antenatal and postnatal care attendant mothers in governmental health centers in Akaki Kality Sub City, Addis Ababa, Ethiopia: hierarchical negative binomial Poisson regression. PLOS ONE. 2017;12(1):e0169415.

20. Negasa M, Tigabu BM. Drug prescribing pattern among pregnant mothers attending obstetrics and gynecology department in Hiwot Fana Specialized Teaching Hospital, Ethiopia. Arch Pharm Pract. 2014;5(2):78.

21. FDA Pregnancy Risk Information: An Update. https://www.drugs.com/ pregnancy-categories.html. Accessed 29 Oct 2018.

22. Pedersen TM, Stokholm J, Thorsen J, Mora-Jensen A-RC, Bisgaard H. Antibiotics in pregnancy increase children's risk of otitis media and ventilation tubes. J Pediatr. 2017;183(153-158):e151.

23. Broe A, Pottegård A, Lamont RF, Jørgensen JS, Damkier P. Increasing use of antibiotics in pregnancy during the period 2000-2010: prevalence, timing, category, and demographics. BJOG. 2014;121(8):988-96.

24. Muanda FT, Sheehy O, Bérard A. Use of antibiotics during pregnancy and risk of spontaneous abortion. Can Med Assoc J. 2017;189(17):E625-33.

25. de Jonge $L$, Bos HJ, van Langen IM, de Jong-van den Berg LT, Bakker MK. Antibiotics prescribed before, during and after pregnancy in the Netherlands: a drug utilization study. Pharmacoepidemiol Drug Saf. 2014:23(1):60-8.

26. Muanda FT, Sheehy O, Bérard A. Use of antibiotics during pregnancy and the risk of major congenital malformations: a population based cohort study. Br J Clin Pharmacol. 2017;83(11):2557-71.

27. Kuperman AA, Koren O. Antibiotic use during pregnancy: how bad is it? BMC Med. 2016;14(1):91.

28. Fontoura A, Ayres LR, Martins-Nagai M, Dewulf NL, dos Santos V, Martinez EZ, Pereira LR. Prevalence of medication use among low risk pregnant women: a drug utilization study. Afr J Pharm Pharmacol. 2014;8(36):883-92.

29. Fikadu M, Kebebe D, Amelo W, Gashe F. Drug utilization pattern and potential teratogenicity risk among pregnant women visiting antenata clinic: the case of a primary hospital. Indian J Pharm Pract. 2015;8(1):27.

30. Chaudhari A, Aasani D, Trivedi H. Drug utilization study in antenatal clinic of Obstetrics Gynaecology Department of a Tertiary Care Hospital attached with Medical College. Indian J Pharm Pharmacol. 2016;3(4):186-91.

31. Devkota R, Khan G, Alam K, Regmi A, Sapkota B. Medication utilization pattern for management of pregnancy complications: a study in Western Nepal. BMC Preg Childbirth. 2016;16(1):272.

32. Inamdar I, Aswar M, Sonkar V, Doibale M. Drug utilization pattern during pregnancy. Indian Med Gazette. 2012;146:305-11. 
33. Sasidharan P, Kolasani BP, Divyashanthi C. An observational prospective study on prescribing pattern of drugs among pregnant women admitted in antenatal ward of a tertiary care teaching hospital in coastal town of South India. Natl J Physiol Pharm Pharmacol. 2017;7(1):25.

34. Beza SW. Self-medication practice and associated factors among pregnant women in Addis Ababa, Ethiopia. Trop Med Health. 2018;46(1):10.
35. Patel KP, Joshi HM, Patel VJ. A study of morbidity and drug utilization pattern in indoor patients of high risk pregnancy at tertiary care hospital. Int J Reprod Contr Obstet Gynecol. 2016;2(3):372-8.

36. Varghese BM, Vanaja K, Banu R. Assessment of drug usage pattern during pregnancy at a tertiary care teaching Hospital. Int J Med Public Health. 2016;6(3):130.
Ready to submit your research? Choose BMC and benefit from:

- fast, convenient online submission

- thorough peer review by experienced researchers in your field

- rapid publication on acceptance

- support for research data, including large and complex data types

- gold Open Access which fosters wider collaboration and increased citations

- maximum visibility for your research: over 100M website views per year

At BMC, research is always in progress.

Learn more biomedcentral.com/submissions 